\section{УДК 617-089.844}

\section{ВАК 14.01.18; 14.01.15}

А.В. Яриков, ${ }^{1-2}$ О.А. Перльмуттер, ${ }^{2}$ А.П. Фраерман, ${ }^{2}$ А.А. Бояршинов, ${ }^{2}$ А.Г. Соснин, ${ }^{1}$ И.В. Гунькин, ${ }^{3}$ С.Е. Тихомиров ${ }^{2}$

ФБУЗ «Приволжский окружной медицинский центр» ФМБА России ${ }^{1}$ г. Нижний Новгород

ГБУЗ НО «Городская клиническая

больница №39»²

г. Нижний Новгород

ГБУЗ МО «Мордовская республиканская центральная клиническая больница» ${ }^{3}$ г. Саранск

\section{ОСЛОЖНЕНИЯ И ОШИБКИ ОПЕРАТИВНО-} ГО ЛЕЧЕНИЯ ПОВРЕЖДЕНИЯ ГРУДНЫХ И ПОЯСНИЧНЫХ ПОЗВОНКОВ

Введение. Доля травмы позвоночника составляет 0,7-8,0\% в структуре закрытой травмы и 5,0-20,3\% среди повреждений опорно-двигательного аппарата [1-4]. За последние 70 лет количество больных с позвоночно-Спинномозговой травмой (ПСМТ) возросло в 200 раз [4-6]. В России ежегодно регистрируется около 8-9 тысяч случаев ПСМТ, на Украине - около 2-х тысяч, в США - 15 тысяч $[1,3,5,7,8]$. Сочетанная ПСМТ фиксируется у 13 - 76\% пострадавших [57]. При сочетанной ПСМТ летальность в 4 раза выше, чем при изолированной. Более чем в $80 \%$ случаев ПСМТ является прерогативой лиц 15-45 лет, соотношение мужчин и женщин 3:1 [3, 6, 9]. Среди причин ПСМТ доминируют ДТП (27,1-43,0\%) и кататравма $(15,8-63,2 \%)$. Летальность при ПСМТ в основном зависит от тяжести повреждения спинного мозга (СМ) - до 37\% пострадавших погибают на догоспитальном этапе. Инвалидность при
ПСМТ варьирует в пределах от 57,5 до $96 \%$, а иногда достигает $100 \%$ [3]. ПСМТ первоначально определяют ортопедический аспект мероприятий (восстановление опорной и защитной функций позвоночника), а сдавление СМ и/или его корешков нейрохирургический (восстановление функций СМ) [3]. Нестабильные поражения в нижнем грудном (ГОП) и поясничном отделах позвоночника (ПОП) из всех повреждений позвоночного столба встречаются наиболее часто - до 54,9\% [10]. При травме ГОП и ПОП повреждение СМ наблюдается в 31-75\% случаев [3]. Пациенты с ПСМТ насчитывают 2-3\% от всех больных, госпитализируемых в нейрохирургические отделения [2]. Проблема лечения пострадавших С ПСТ является острой проблемой отечественной нейрохирургии [5, 8, 11-13].

$\begin{array}{llll}\text { В } 2015 & \text { г. по поводу ПСМТ в } \\ \text { России } & \text { было прооперировано около } \\ 8900 \text { человек. } & \text { По большей части }\end{array}$
По большей части это объясняется тем обстоятельством, что в большинстве регионов России отсутствует современная система оказания неотложной высокоспециализированной медицинской помощи больным с ПСМТ $[5,8,11,13]$. Большое значение имеет полноценное оснащение стационара диагностическим оборудованием (КТ, МРТ, С-дуга), современными имплантируемыми металлоконструкциями и наличием устойчивого финансирования [7, 12, 14-16]. Ошибки, возникающие при хирургическом лечении ПСМТ, можно распределить следующим образом: тактические, технические и ошибки, допущенные больным; выявленные осложнения - на неврологические, повреждения внутренних органов, инфекционные. По периоду возникновения ошибки и осложнения можно распределить на интраоперационные, ранние (до 2 недель) и поздние послеоперационные (свыше 2 недель) [17].

Резюме За последние 70 лет количество пострадавших с позвоночно-спинномозговой травмой выросло в 200 раз. В России ежегодно регистрируется около 8-9 тысяч случаев позвоночно-спинномозговой травмы, в 80\% случаев это является прерогативой лиц 15-45 лет. Проблема лечения пострадавших с травмой позвоночника является острой проблемой отечественной нейрохирургии. В статье представлен обзор литературы, посвященный ошибкам нейрохирургического лечения повреждений грудных и поясничных позвонков. Из основных тактических ошибок авторы выделили неадекватную инструментальную фиксацию при крайне нестабильных переломах (тип В и С). В работе затронуты причины формирования посттравматической деформации позвоночника. Так же выделены следующие тактические ошибки: неадекватная декомпрессия, отказ или неудачи в коррекции деформации, целенаправленное разрушение задней опорной колонны. Техническими ошибки представлены: нарушения в технике имплантации металлоконструкции, перелом и мальпозиция стержней; перелом, дислокация и мальпозиция транспедикулярного винта. Пристальное внимание уделено ошибкам, допущенным пациентом и недостаткам металлоконструкций. Особое внимание уделено инфекционным (пневмония, уроинфекция, пролежни, нагноение послеоперационной раны) и неврологическим (ликворея, дуротомия, радикулопатия) осложнениям. Подробно изучены причины этих осложнений и предложены мероприятия по их снижению. В заключение авторами предложены пути по снижению осложнений оперативного лечения позвоночноспинномозговой травмы.

Ключевые слова: перелом позвонка, мальпозиция винта, транспедикулярный остеосинтез, посттравматическая деформация позвоночника, транспедикулярный винт. 


\section{Тактические ошибки}

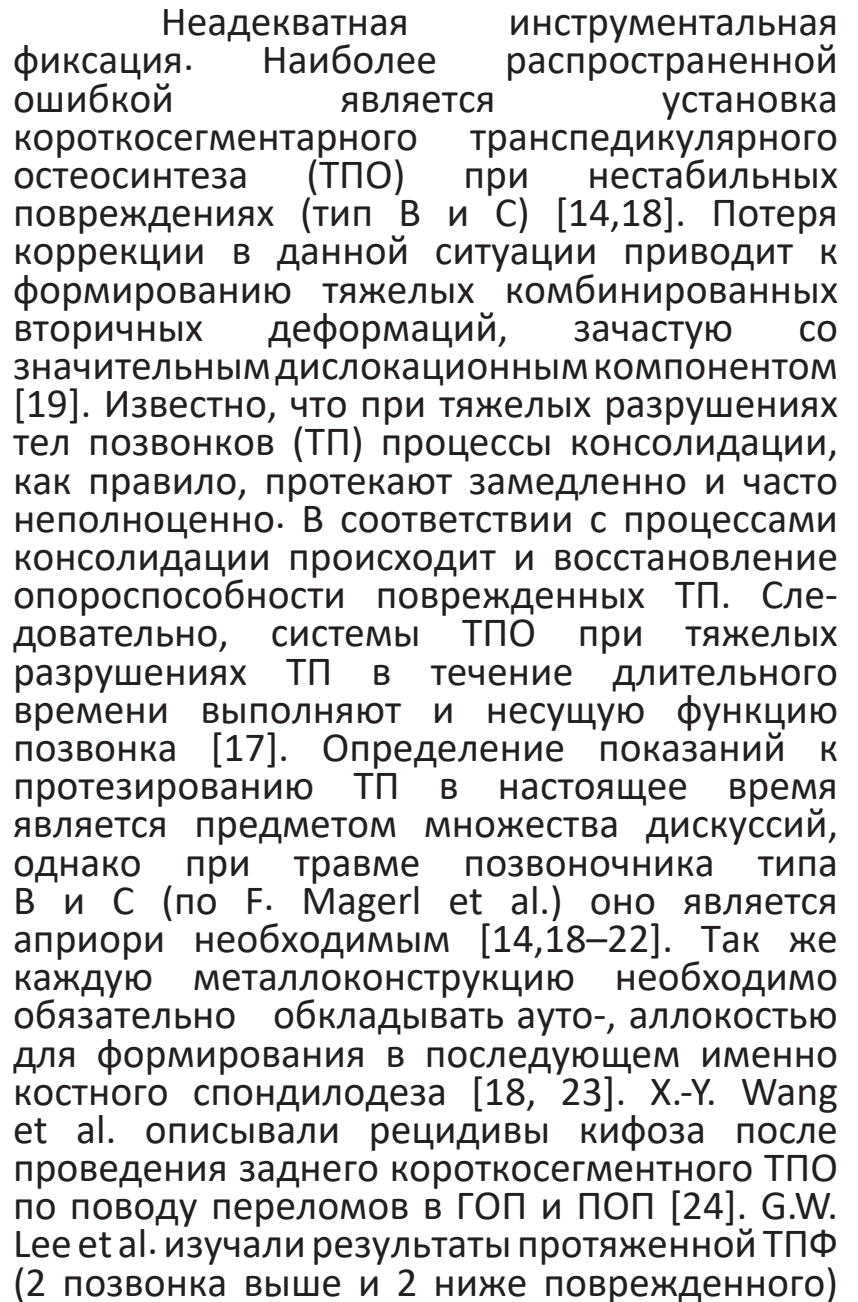

при различных повреждениях в ГОП и ПОП [25]. Авторы оценивали угол кифотической деформации в градусах и передний размер позвонка в процентах. Оказалось, что через два года происходило нарастание кифотической деформации на $3,7^{\circ}$ и уменьшение переднего размера позвонка на 6\%. У одного пациента из 27 пролеченных был выявлен перелом только одного транспедикулярного винта (ТПВ), что указывает на предпочтение протяженного ТПО перед короткосегментарным при ПСМТ.

Неадекватная декомпрессия. Причинами сохраняющегося сдавления СМ и его корешков в позвоночном канале являются отказ от выполнения декомпрессии, ляминектомия на недостаточном протяжении (обычно резекция дуги только сломанного позвонка), ошибки в определении уровня сдавления CM (рис. 1) [11, 23, 26-28]. Недостаточная декомпрессия приводит к ущемлению СМ вследствие отека в декомпрессионном «окне» и формированию дистанционного некроза [29]. Доказано, что ламинэктомию нужно выполнять на один уровень выше и ниже перелома, иначе в малом ламинэктомическом "окне» происходит еще большее вторичное повреждение из-за ущемления СМ при продолжающемся отеке $[12,21]$.

Отказ или неудачи в коррекции деформации. Нестабильность, развивающаяся вследствие ненадежной стабилизации, может сопровождаться образованием псевдоартроза на уровне инструментальной фиксации без проявления клинически

COMPLICATIONS AND ERRORS OF SURGICAL TREATMENT OF DAMAGE TO THE THORACIC AND LUMBAR VERTEBRAE

A.V. Yarikov, ${ }^{1-2}$ O.A. Perlmutter, ${ }^{2}$ A.P. Fraerman, ${ }^{2}$ A.A. Boyarshinov, ${ }^{2}$ A.G. Sosnin, ${ }^{1}$ I.V. Gunkin, ${ }^{3}$ S.E. Tikhomirov $^{2}$

Federal State Health Institution "Volga Regional Medical Center", Nizhny Novgorod; ${ }^{1}$ GBUZ NO "City Clinical Hospital No. 39", Nizhny Novgorod;" GBUZ MO "Mordovian Republican Central Clinical Hospital", Saransk. ${ }^{3}$

Abstract Over the past 70 years, the number of victims with spinal cord injury has increased by 200 times. Russia annually recorded about 8-9 thousand cases of spinal cord injury, in $80 \%$ of cases it is the prerogative of persons of 15-45 years. The problem of treatment of victims with spinal injury is an acute problem of domestic neurosurgery. The article presents a review of the literature on the errors of neurosurgical treatment of injuries of thoracic and lumbar vertebrae. Of the main tactical errors, the authors identified inadequate instrumental fixation in extremely unstable fractures (type B and C). The paper deals with the causes of post-traumatic deformation of the spine. The following tactical errors are also identified: inadequate decompression, failure or failure in deformation correction, purposeful destruction of the rear support column. Technical errors: violations in the technique of metal implantation, fracture and malposition of rods; fracture, dislocation and malposition of transpedicular screw. Close attention is paid to the mistakes made by the patient and the shortcomings of metal structures. Particular interest is paid to infectious (pneumonia, uroinfection, bedsores, suppuration of postoperative wounds) and neurological (liquorrhea, durotomy, radiculopathy) complications. The causes of these complications were studied in detail and measures to reduce them were proposed. In conclusion, the authors proposed ways to reduce the complications of surgical treatment of spinal cord injury.

Key words: vertebral fracture, screw malposition, transpedicular osteosynthesis, posttraumatic deformation of the spine, transpedicular screw 


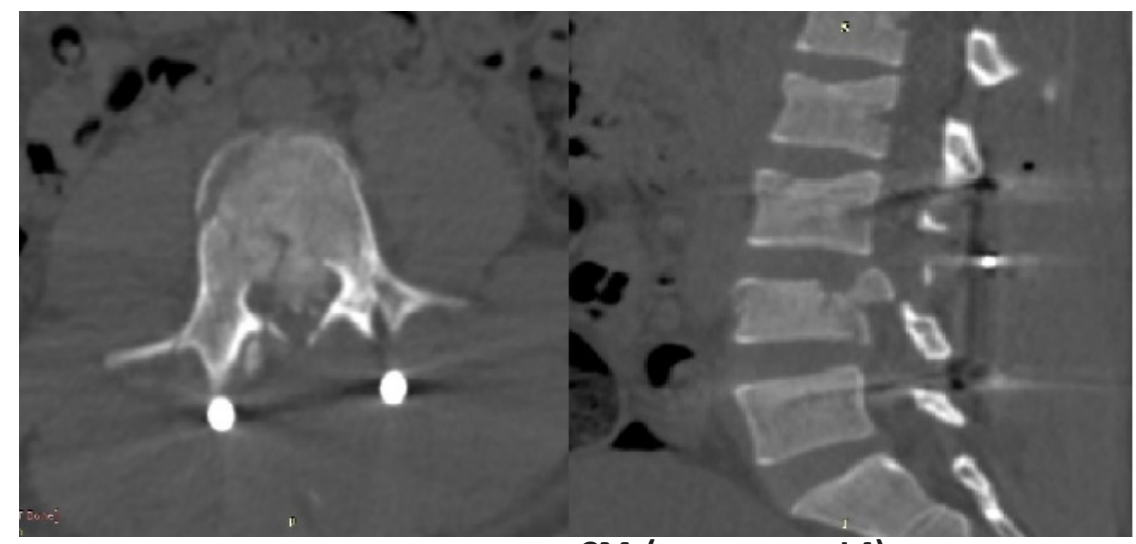

Рисунок 1. Неадекватная декомпрессия корешков CM (на уровне L4) после выполнения TпO L3-L5 и неполной ляминектомии L4.

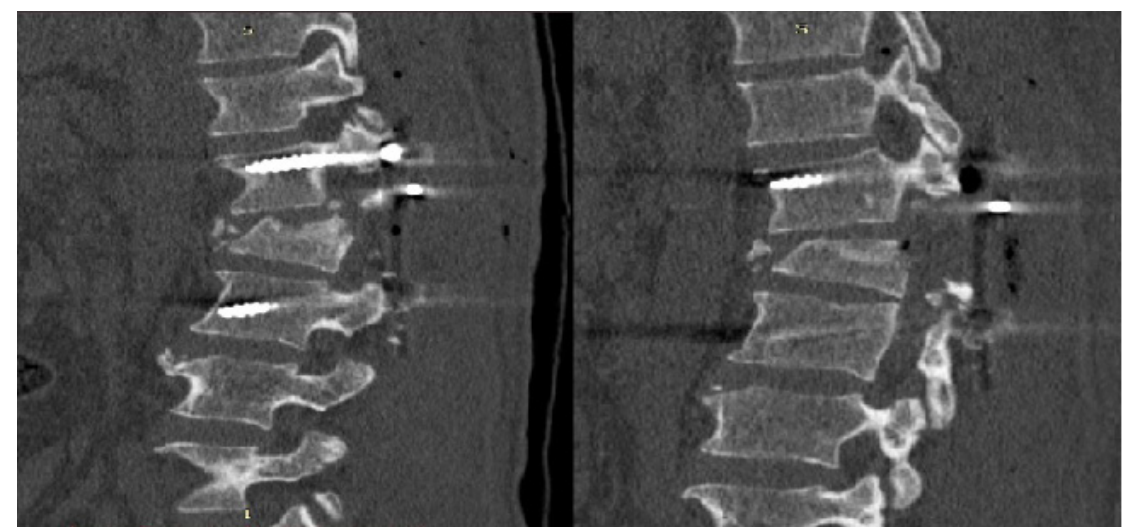

Рисунок 2. Короткосегментарная фиксация (TПO Th12-L2, ляминектомия L1) при переломе TП L1. Невозможность выполнения коррекции кифотической деформации.

прогрессирующей деформации и признаков компрессии СМ и корешков. Однако следует отметить, что, чем больше угловая деформация при не устраненных кифозах на уровне зафиксированных сегментов, тем выше риск псевдоартроза. Угловая деформация <30 градусов приводит к хронической боли в области деформации (у 40-90\% больных), что обусловлено перерастяжением дурального мешка, а при угловой деформации >30 градусов развивается компрессия СМ, вплоть до синдрома его поперечного поражения с развитием мелопатических изменений [28]. Кроме нестабильности и псевдоартроза вследствие неадекватного выбора стабилизации причиной вертеброгенной боли может быть и так называемый синдром смежного сегмента. Некоторые авторы считают основополагающим фактором ригидность установленной конструкции, которая приводит к перегрузке прилежащих сегментов до $30-60 \%$. Повреждение интактных суставов при ТПФ способствует формированию нестабильности [29]. Если в результате операции не устраняется сагиттальная и фронтальная деформация, прилежащий сегмент стремится компенсировать баланс и нормальную биомеханику позвоночника, при этом риск его повреждения увеличивается [28, 47-49]. Отказ от выполнения хирургической коррекции (рис. 2), применение избыточной дистракции в ПОП приводит к сглаживанию поясничного лордоза и, как следствие, к статическим нарушениям [11]. Коррекция деформаций с по- мощью имплантатов возможна только при использовании современных лицензированных спинальных систем [11, 30].

Целенаправленное разрушение элементов задней опорной колонны. Как известно, фасеточно-лигаментозный комплекс играет большую роль в поддержании сагиттального баланса позвоночника [31, 32], поэтому неоправданные ляминофасетэктомии увеличивают риск возникновения вторичных деформаций $[14,22]$. Биомеханика ГОП такова, что в условиях физиологического кифоза основными элементами, обеспечивающими стабильность в сагиттальной плоскости, являются суставные отростки разрушение которых приводит к формированию грубых комбинированных вторичных деформаций, нередко сопровождающихся появлением или усугублением неврологической симптоматики. ПОП более устойчив к дислокациям в сагиттальной плоскости, что во многом обусловлено физиологическим лордозом, формой позвонков и мощным лигаментозным комплексом, поэтому сагиттальных смещений при повреждениях типа А после первичных ляминофасетэктомий не наблюдается. Однако суставные отростки ограничивают боковые, а также вращательные смещения и удаление их в ряде случаев послужило причиной латеролистеза и умеренных ротационных деформаций [14]. 


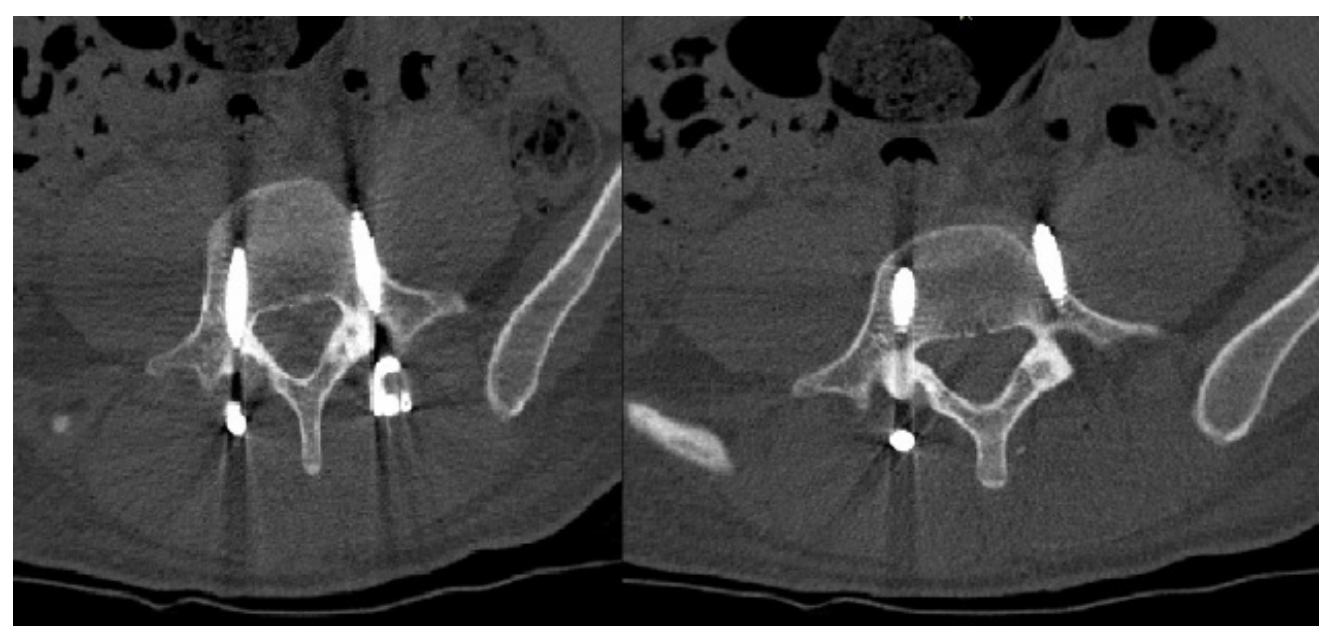

Рисунок 3. Латеральная мальпозиция ТПВ в ТП L5 слева. Выход ТПВ за пределы ТП.

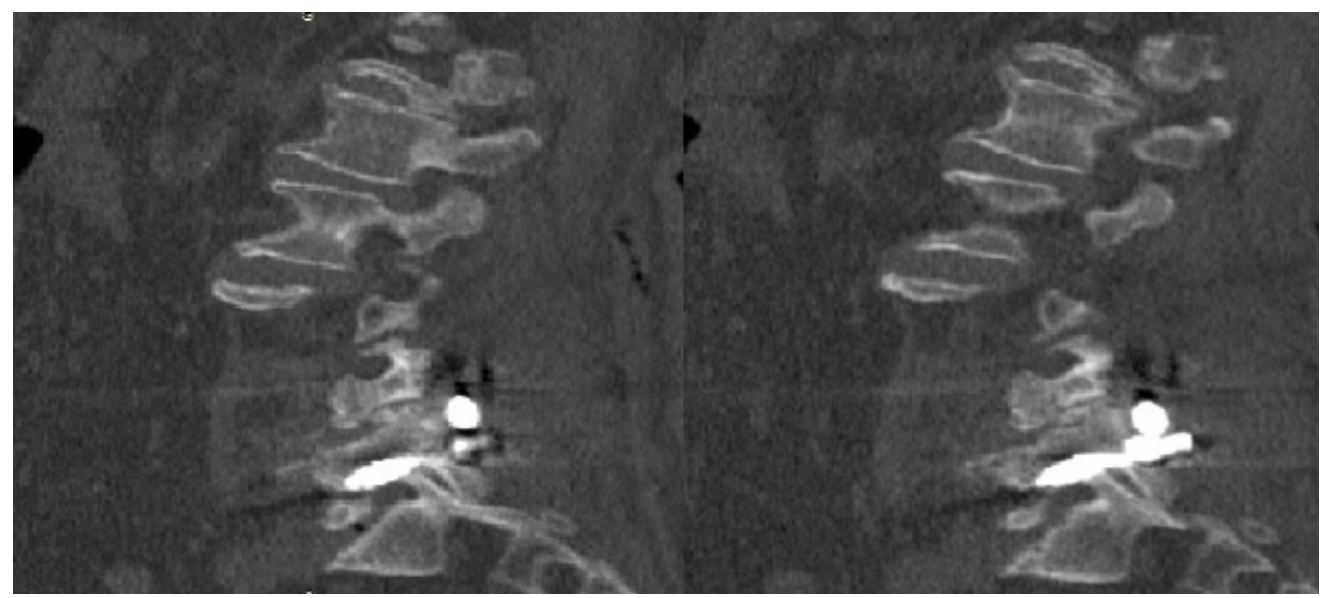

Рисунок 4. ТПВ располагается в фораминальном отверстии.

\section{Технические ошибки в процессе имплантации металлоконструкций}

\author{
Ошибки в технике имплантации \\ металлоконструкции. Многократное \\ формирование канала для ТПВ и его \\ постановка в сломанную ножку приводит к \\ нестабильности ТПФ [33, 34].
}

Отклонение траектории в проведениях ТПВ в различных плоскостях чревато осложнениями и встречается в 2,8-20,0\% [14, 35-37]. Чаще перфорируется наружная стенка ножки дуги, вследствие чего ТПВ проходил кнаружи от ТП (рис. 3).

При установке ТПВ полностью или частично экстрапедикулярно приводит к его прорезыванию и возникает потеря коррекции во фронтальной плоскости [14]. Смонтированная данная конструкция уже первоначально становится недостаточно стабильной, возникает микроподвижность в области фиксации, что приводит к появлению вертеброгенного болевого синдрома, резорбции костной ткани вокруг ТПВ и их миграции $[28,38]$. Так же при проведении ТПВ перфорируются нижняя (рис. 4) или верхняя кортикальные стенки ножки позвонка с проваливанием его в диск [10, 11, 33, 38, 39].
Мальпозиция ТПВ при разрушении нижней и медиальной стенок ножки (рис. 5) может приводить к повреждению и компрессии невральных структур, что в дальнейшем является причиной стойких корешковых болевых синдромов [28, 38, 39]. Медиальная мальпозиция считается, если ТПВ располагается более $1 / 3$ своего диаметра в позвоночном канале или более 2 мм [40]. Медиальное отклонение ТПВ более 6 мм увеличивает риск повреждения СМ (особенно выше L2 позвонка) и его корешков.

При выявлении клинических и рентгенологических признаков мальпозиции ТПВ единственная тактика оперативного лечения заключаетсяв проведенииповторного оперативного вмешательства [34, 35, 40, 41]. Корректной установки ТПВ можно достичь при соблюдении следующих условий: применение интраоперационной визуализации (С-дуга, компьютерная томография, нейронавигация), знание анатомии позвоночника, проведение предоперационного планирования (измерение размеров ножек, углов для введения ТПВ), применение сертифицированных имплантов $[28,42]$.

Установка ТПВ диаметром, не соответствующим размеру ножки позвонка, так же способствует процессу резорбции 


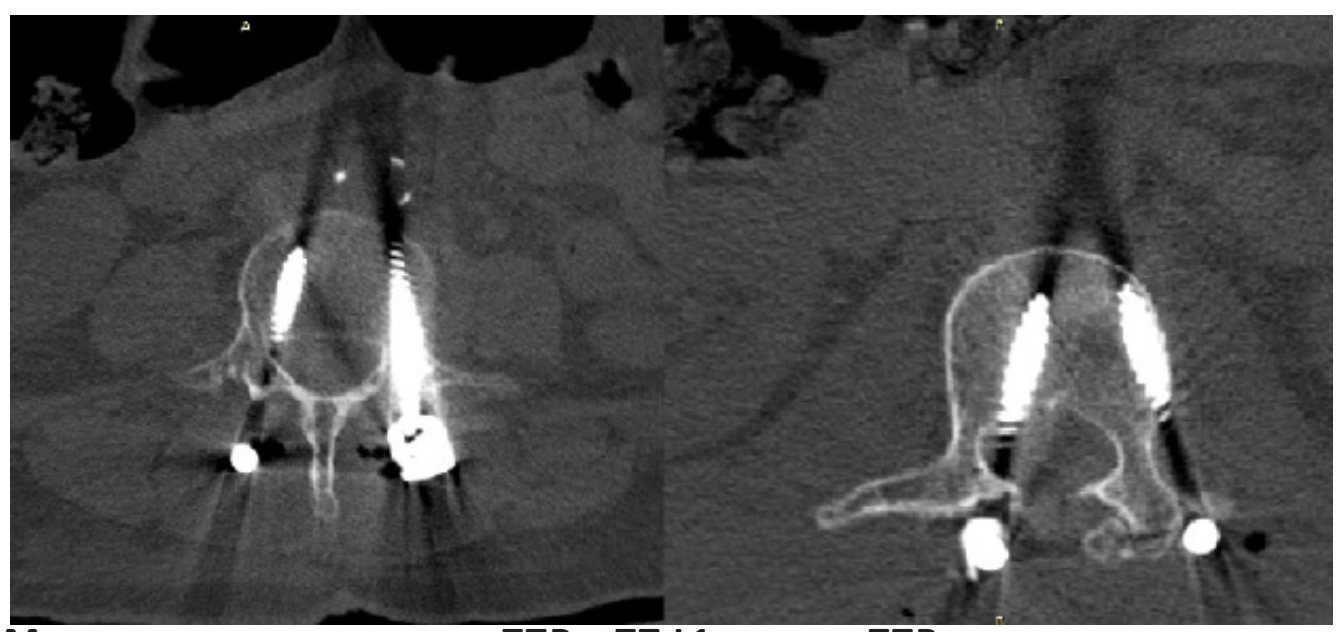

Рисунок 5. Медиальная мальпозиция ТПВ в TП L1 справа. ТПВ на весь диаметр располагается в позвоночном канале.

$[28,34,43]$. Появление на спондилограммах резорбционного ареола в зоне контакта винта и костной ткани - один из первых признаков псевдоартроза и несостоятельности ТПВ. Дестабилизация ТПО за счет резорбции вокруг ТПВ колеблется от 1,7 до 9\% [33]. Кроме того, на развитие несостоятельности конструкции влияет направление ТПВ при установке [28].

\section{В последние годы при травматических деформациях часто используют полиаксиальные ТПВ, удобные при установке и моделировании стержня. Однако, по данным проведенных исследований, использование полиаксиальных ТПВ снижает ригидность конструкции, приводит к нарушению жесткости блока ТПВ-стержень и в дальней- шем может стать причиной костной резорб- ции. В связи с этим на практике комбинируют моно- и полиаксиальные ТПВ [28].}

Перелом и мальпозиция стержней, перелом и дислокация ТПВ. Встречается в 2,8-18,0\% случаев [34, 39]. Причинами этого осложнения бывают дефекты в крепеже ТПВ к стержням или пластинам (перекос или недотягивание гайки, срезание резьбы с гайки при ее перетягивании), несоответствие размеров фиксаторов и массы позвонков (тонкие или короткие ТПВ), частичное вывинчивание ТПВ после его установки (обычно это бывает с моноаксиальными ТПВ, которые вывинчивают для укладки в него стержня), неадекватная фиксация, отсутствие спондилодеза и выраженный остеопороз (приводит в подвижности ТПВ) [33, 42]. При многоуровневой ТПО необходимо изгибать стержни в соответствии с физиологическими изгибами ГОП и ПОП, чтобы стержень не вырвал ТПВ из ТП [42].

Ошибки, допущенные пациентом. Данные осложнения в настоящее время являются следствием неадекватного послеоперационного поведения пациентов, которым разрешена ранняя и чрезмерная активность, и несоблюдение реабилитационного режима $[14,26]$. Не санкционированные лечащим врачом попытки ходьбы, сидения, прекращения фиксации корсетом и физических нагрузок должны быть предупреждаемы четкими инструкциями, зафиксированными в медицинской документации [34, 39]. Это может привести к переломам и мальпозиции стержней, переломам и дислокациям ТПВ $[34,39]$. Профилактика переломов стержней и ТПВ основывается на широком применении переднего спондилодеза [10, 30, 34, 44-46].

Ошибки, связанные с недостатками металлоконструкций. Некачественные металлоимпланты в настоящее время все так же иногда встречаются в практике нейрохирурга [47 - 49]. Дефекты металла, недостаточная толщина штанг, чрезмерно сложная конструкция гаек и запирающего устройства $[30,33,50]$. В настоящее время имеется множество производителей сертифицированных и хорошо зарекомендовавших себя имплантов для ТПО и вентрального спондилодеза: Stryker, "Конмет», TRAUSON, «Медин-Урал», ZIMMER, «Остеосинтез», «Медбиотех» и др. [51-59].

\section{Инфекционные осложнения}

Нагноение операционной раны встречается в 2,0-5,5 \% и зависит от ряда причин [10, 33, 36]. Основная - это ослабленный иммунитет за счет травмы и фоновой иммунодепрессии (у лиц без определенного места жительства, ослабленных различной хронической патологией, инфекциями, алкоголизмом) $[27,29,42,44]$. Другими причинами является кровопотеря более 800 мл, сахарный диабет, ожирение [42]. При нагноении операционной раны проводится ревизия и санация раны c еe приточно-отточным дренированием, назначают массивную антибактериальную терапию и заживляют рану через вторичные швы [45]. Глубокие воспалительные процессы (флегмона, абсцесс, спондилит) встречается в 0,6-3,0\% случаев [44, 45]. Широкое внедрение В хирургическую 
практику методов имплантации массивных инородных тел привело к увеличению числа поздних воспалительных осложнений. Одни вертебрологи считают, что причиной развития мягкотканых воспалительных реакций является нестабильность зафиксированного сегмента, приводящая к травматизации прилежащих тканей металлоконструкцией, а также имбибицией их частицами металла [28]. При дальнейшем нарастании нестабильности и снижении иммунореактивности организма происходит активация вялотекущего воспалительного процесса с образованием свищевых ходов, глубоким распространением в костные структуры и вовлечением эпидурального пространства позвоночного канала [28]. Однако большинство авторов придерживаются мнения, что эти воспалительные явления носят инфекционный характер. Причиной инфекции является нормальная флора кожи человека, проникающая в рану в период первичной операции с последующим холодным периодом [28].

у 30-70\% пациентов формируется уроинфекция, обусловленная постоянным мочевым катетером, установленным в связи с нарушением функции тазовых органов. Присутствие воспаления мочеполовой системы коррелирует и с появлением других осложнений:ТЭЛА, сепсисом, дисбактериозом, парезом кишечника, пролежнями. Профилактикой уроинфекции представляется отказ от использования постоянного катетера и переход на периодическую катетеризацию 4-6 раз в день. При ассистируемом опорожнении мочевого пузыря необходимо контролировать у пострадавшего количество выделяемой мочи, которое в целях профилактики воспалительных заболеваний не должно превышать 400 мл. В противном случае кратность суточных катетеризаций следует увеличить. Желательно использование одноразовых катетеров с любрикантами (покрытые поливинилпирролидоном) вплоть до формирования спинального автоматизма [42].

Развитие пневмонии у лиц с ПСМТ (обычно на 5-6-е сутки) обусловлено как сочетанной травмой с повреждением грудной клетки, так и осложненным характером перелома позвоночника, а также аспирацией и гипостатическим компонентом. Количество пострадавших с пневмонией в группе лиц с изолированной ПСМТ достоверно ниже. Сочетанность ПСМТ увеличивает количество пострадавших с пневмонией, но не влияет на сроки ее появления, которые одинаковы в двух группах, что свидетельствует о единых механизмах развития пневмонии независимо от вида травмы. Развитие пневмонии коррелирует с тяжестью общего состояния больного. Зная высокую частоту развития пневмонии у больных с осложненной ПСМТ (шейный и грудной уровни) нужно производить аускультацию легких каждый день. При подозрении на развитие пневмонии надо выполнить рентгенографию легких, а при длительно текущем процессе - рентгеновскую компьютерную томографию органов грудной клетки. С целью профилактики пневмонии проводят дыхательную гимнастику, раннюю активизацию, вибромассаж грудной клетки, санационную бронхоскопию, ЛФК, массаж $[18,42]$.

Высок риск образования пролежней у больных с осложненной и сочетанной ПСМТ. Наличие пролежней увеличивает средний койко-день и способствует возникновению целого ряда осложнений: сепсиса, ТЭЛА, печеночной и почечной недостаточностей. В стационарах, занимающихся лечением ПСМТ, развития пролежней не допускают. Доказано, что повороты пострадавшего с первого часа после поступления и должный уход обходятся значительно дешевле, чем последующее лечение пролежней, которое затягивается на месяцы и не позволяет проводить полноценную раннюю реабилитацию пациентов. Вылечить пролежень значительно труднее и дороже, чем его не допустить [42].

Сочетание уроинфекции, пневмонии, пролежней у 5\% пострадавших с ПСМТ приводит к развитию сепсиса.

\section{Неврологические}

осложнения. После проведения ТПО неврологические осложнения составляют от 1,1 до $2 \%$ [33, 44, 46]. Дуротомия с развитием ликвореи - 4,2\%, транзиторная нейропраксия - 2,4\%, стойкое повреждение корешков СМ - 2,3\% [17, 33]. При интраоперационном повреждении дурального мешка в момент постановки ТПВ проводится тампонирование гемостатической губкой костного канала и переустановка ТПВ [50].Герметизациятвердоймозговойоболочки - основное мероприятие для профилактики осложнений в постоперационном периоде [55]. Доказано, что оптимальным методом закрытия дефекта твердой мозговой оболочки при ПСМТ представляется расширяющая пластика [56, 57]. В настоящее время описаны различные варианты расширяющей пластики с использованием аутологичного жира, фасции и мышечного лоскута, ксенотрансплантатов, синтетических заменителей твердой мозговой оболочки и их комбинации с фибриновым клеем $[50,60]$. После зашивания твердой мозговой оболочки нужно провести пробу Квеккенштедта, Стуккея [18, 42]. При развитии ликвореи из раны накладывают дополнительные швы на кожу, давящую повязку, назначают строгий постельный режим [45].

\section{Заключение}

Несмотря на достижения вспинальной нейрохирургии, сохраняется актуальной проблема осложнений и ошибок при хирургическом лечении ПСМТ. Мероприятия, направленные на предупреждение 
ошибок и осложнений при ТПО, включают обоснование числа фиксируемых позвонков и вариантов установки металлоконструкции, индивидуальный подбор ТПВ по диаметру и длине погружной части, их корректная установка, а также правильное ушивание и дренирование раны.

\section{Литература}

1. Гринь А.А., Некрасов М.А., Кайков А.К., Ощепков С.К., Львов И.С., Иоффе Ю.С., Крылов В.В. Алгоритмы диагностики и лечения пациентов с сочетанной позвоночноспинномозговой травмой. Хирургия позвоночника. 2012. № 1. С. 8-18.

2. Крылов В.В., Гринь А.А., Луцик А.А., Парфенов В.Е., Дулаев А.К., Мануковский В.А., Коновалов Н.А., Перльмуттер О.А., Сафин Ш.М., Кравцов М.Н., Манащук В.И., Рерих В.В. Рекомендательный протокол лечения острой осложненной и неосложненной травмы позвоночника у взрослых (Ассоциация нейрохирургов РФ). Часть 1. Вопросы нейрохирургии им. Н.Н. Бурденко. 2014. Т. 78. № 6. С. 60-67.

3. Морозов И.Н., Млявых С.Г. Эпидемиология позвоночно-спинномозговой травмы.

Медицинский альманах. 2011. № 4 (17). С. 157-159.

4. Усиков В.Д., Воронцов К.Е., Куфтов В.С., Ершов Н.И. Ближайшие и отдаленные результаты хирургического лечения позвоночно-спинномозговой травмы грудного и поясничного отделов. Травматология и ортопедия России. 2014. № 2 (72). С. 37-44.

5. Гринь А.А., Николаев Н.Н., Горохова Е.H. Множественные и многоуровневые повреждения позвоночника (часть 1). Нейрохирургия. 2008. № 3. С. 47-55.

6. Глазков Р.В., Берснев В.П., Верещако А.В., Позин В.В., Маршалкин С.М. Возможность использования интегральных систем оценки тяжести травмы у пострадавших с повреждением позвоночника на этапе поступления в стационар. Скорая медицинская помощь. 2012. T. 13. № 2. С. 80-83.

7. Ахмеджанов Ф.М., Карякина У.В., Гринь А.А. Алгоритм лучевого исследования при закрытой травме нижнешейного отдела позвоночника. Нейрохирургия. 2007. № 3. С. 43-49.

8. Баринов А.Н., Кондаков Е.Н. Организация помощи пострадавшим с позвоночноспинномозговой травмой в Архангельской области. Нейрохирургия. 2011. № 3. С. 73-78.

9. Сороковиков В.А., Бывальцев В.А., Калинин А.А., Панасенков С.Ю., Егоров А.В. Современные подходы к лечению пациентов с позвоночно-спинальной травмой. Acta
Biomedica Scientifica. 2011. № 1-2 (77). C. 272274.

10. Говенько Ф.С., Монашенко Д.Н., Лукин Д.С. Исходы хирургического лечения пациентов с нестабильным поражением позвонков грудной и поясничной локализации. Вестник Российской военно-медицинской академии. 2012. № 1 (37). С. 150-153.

11. Дулаев А.К., Хан И.Ш., Дулаева Н.М. Причины неудовлетворительных анатомофункциональных результатов лечения больных с переломами грудного и поясничного отделов позвоночника. Хирургия позвоночника. 2009. № 2. С. 17-24.

12. Аганесов А.Г. Хирургическое лечение осложненной травмы позвоночника прошлое и настоящее. Хирургия. Журнал им. Н.И. Пирогова. 2013. № 1. С. 5-12.

13. Баринов А.Н., Кондаков Е.Н. Клиникостатистическая характеристика острой позвоночно-спинномозговой травмы. Хирургия позвоночника. 2010. № 4. С. 15-18.

14. Шульга А.Е., Зарецков В.В., Островский В.В., Арсениевич В.Б., Смолькин А.А., Норкин И.А. К вопросу о причинах развития вторичных посттравматических деформаций грудного и поясничного отделов позвоночника. Саратовский научно-медицинский журнал. 2015. T.11. № 4. C. 570-575.

15. Крылов В.В., Гринь А.А., Иоффе Ю.С., Казначеев В.М., Николаев Н.Н., Некрасов М.A. Лечение больных с осложненными и неосложненными повреждениями позвоночника при сочетанной травме. Хирургия позвоночника. 2005. № 4. С. 8-14.

16. Щербук Ю.А., Багненко С.Ф., Дулаев А.К., Дулаева Н.М., Аликов 3.Ю. Организация специализированной медицинской помощи пациентам с неотложной хирургической патологией позвоночника. Хирургия позвоночника. 2011. № 2. С. 67-73.

17. Прудникова О.Г. Подходы к классификации ошибок и осложнений наружного транспедикулярного остеосинтеза. Медицинский альманах. 2012. № 5 (24). С. 171-174.

18. Гринь А.А., Кайков А.К., Крылов В.В. Осложнения и их профилактика у больных с позвоночно-спинномозговой травмой (часть 2). Нейрохирургия. 2015. № 1. С. 55-66.

19. Фраерман А.П., Сыркина Н.В., Железин О.В., Гомозов Г.И., Акулов М.С. и др. Сочетанная черепно-мозговая травма. Поволжье. Нижний Новгород. 2015: 204 с.

20.КрыловВ.В.,ГриньА.А., ЛуцикА.А.,Парфенов В.Е., Дулаев А.К. и др. Рекомендательный протокол лечения острой осложненной и 
неосложненной травмы позвоночника у взрослых (Ассоциация нейрохирургов РФ). Часть 3. Вопросы нейрохирургии им. Н.Н. Бурденко. 2015. Т. 79. № 2. С. 97-110.

21. Рамих Э.А. Повреждения грудного и поясничного отделов позвоночника. Хирургия позвоночника. 2008. № 2. С. 94-114.

22. Дулаев А.К., Мануковский В.А., Кутянов Д.И. Позвоночно-спинномозговая травма. СанктПетербургский НИИ скорой помощи им. И.И. Джанелидзе, под ред. проф. В.Е. Парфенова. Санкт-Петербург ООО «Фирма «Стикс»». 2018. C. 48 .

23. Фраерман А.П., Кравец Л.Я., Шелудяков А.Ю., Трофимов А.О., Балябин А.В. Сдавление головного мозга при изолированной и сочетанной черепно-мозговой травме. Поволжье. 2008. С. 328.

24. Wang X.-Y., Dai L.-Y., Xu H.-Z. [et al.]//Kyphosis reccurence after posterior short-segment fixation in thoracolumbar burst fractures. J. Neurosurg. Spine. 2008. Vol. 8. № 3. P. 246.

25. Lee G.W., Jang S.J., m Kim J.D., Son J.H., Jang J.H. The efficacy of percutaneous long-segmental posterior fixation of unstable thoracolumbar fracture with partial neurologic deficit. //Asian Spine J. 2013. Vol. 7(2). P. 81-90.

26. Афаунов А.А., Басанкин И.В., Кузьменко A.B., Мишагин А.В. Ревизионные операции В хирургическом лечении повреждений грудногоипоясничногоотделовпозвоночника. Вестник физиотерапии и курортологии. 2015. T.21. №2. C.98.

27. Перльмуттер О.А., Григорьева В.Н., Курилина Л.Р. Травма позвоночника и спинного мозга: неотложная диагностика и лечение. Нижний Новгород, НижГМА. 2016. С. 96.

28. Нейрохирургия. Том 2. Под редакцией профессора Древаля О.Н.

29. Зуев И.В., Давыдов Е.А., Берснев В.П., Ильин А.А., Коллеров М.Ю. Стабильная и динамическая фиксация при повреждениях и дегенеративно-дистрофических заболеваниях позвоночника. Хирургия позвоночника. 2009. № 3. C. 8-13.

30. Луцик А.А., Бондаренко Г.Ю., Булгаков В.Н., Епифанцев А.Г. Передние декомпрессивностабилизирующие операции при осложненной травме грудного и грудопоясничного отделов позвоночника. Хирургия позвоночника. 2012. № 3. C. 8-16.

31. Vaccaro AR, Lehman RA, Hurlbert RJ, et al. A new classification of thoracolumbar injuries: the importance of injury morphology, the integrity of the posterior ligamentous complex, and neurologic status.// Spine 2005. Vol. 30. P. 2325-2333.
32. Афаунов А.А., Кузьменко А.В. Рабочая классификация травматических стенозов позвоночного канала для повреждений нижнегрудного и поясничного отделов позвоночника. Кубанский научный медицинский вестник. 2016. № 2 (157). С. 1319.

33. Бердюгин К.А., Чертков А.К., Штадлер Д.И., Климов М.Е., Бердюгина О.В. и др. Ошибки и осложнения транспедикулярной фиксации позвоночника погружными конструкциями. Фундаментальные исследования. 2012. №4-2. С. 425-431.

34. Бердюгин К.А., Чертков А.К., Штадлер Д.И., Бердюгина О.В. О неудовлетворительных исходах транспедикулярной фиксации позвоночника. Хирургия позвоночника. 2010. №4. C. 19-24.

35. Бердюгин К.А., Бердюгина О.В., Штадлер Д.И., Гусев Д.А., Штадлер В.Д. Авторские системы для профилактики мальпозиции резьбовых транспедикулярных винтов при фиксации позвоночника погружными конструкциями. Современные проблемы науки и образования. 2015. № 6. С. 5.

36. Кокушин Д.Н., Белянчиков С.М., Мурашко В.В. Хирургическое лечение нестабильных повреждений грудного и поясничного отделов позвоночника. Исторические аспекты. Международный журнал прикладных и фундаментальных исследований. 2016. № 113. С. $442-450$.

37. Бердюгин К.А., Кутепов С.М. К вопросу о неудовлетворительных исходах транспедикулярной фиксации позвоночника. Уральский медицинский журнал. 2010. № 7(72). С. 103-107.

38. Монашенко Д.Н., Бадалов В.И., Кистень B.K. Интраоперационные осложнения в спинальной хирургии. Вестник Российской военно-медицинской академии. 2016. № 4 (56). С. 217-223.

39. Бердюгин К.А., Чертков А.К., Климов М.Е., Бердюгина О.В., Новицкая Е.В. и др. Внеочаговый транспедикулярный остеосинтез В лечении повреждений позвоночника. Основные ошибки и осложнения. Современные проблемы науки и образования. 2012. №5. C. 10.

40. Бердюгин К.А. Алгоритм оперативного лечения у больных с переломами грудных и поясничных позвонков. Фундаментальные исследования. 2013. № 9-4. С. 591-595.

41. Бердюгин К.А., Бердюгина О.В. Остеосинтез позвоночника аппаратами внешней фиксации (обзор литературы). Фундаментальные исследования. 2013. №9-4. С. 765-768.

42. Гринь А.А., Кайков А.К., Крылов В.В. 
Осложнения и их профилактика у больных с позвоночно-спинномозговой травмой (часть 1). Нейрохирургия. 2014. № 4. С. 75-86.

43. Валеев И.Е., Валеев Е.К. Особенности транспедикулярного спондилодеза при повреждениях грудопоясничных позвонков. Практическая медицина. 2013. № 2-2 (68). С. 25-28.

44. Бердюгин К.А., Каренин М.С. Осложнения транспедикулярной фиксации позвоночника и их профилактика. Фундаментальные исследования. 2010. № 9. С. 61-71.

45. Усиков В.В., Усиков В.Д. Ошибки и осложнения внутреннего транспедикулярного остеосинтеза при лечении больных с нестабильными повреждениями позвоночника, их профилактика и лечение. Травматология и ортопедия России. 2006. №1 (39). C.21-26.

46. Басков А.В., Каримов А.А., Борщенко И.А., Древаль О.Н., Дракин А.И. и др. Коррекция неврологических осложнений, возникших после транспедикулярной стабилизации позвоночника. Вопросы нейрохирургии им. Н.Н. Бурденко. 2008. №4. С. 24-30.

47. Дудаев А.К., Усиков В.Д., Пташников Д.А., Фадеев Е.М., Дыдыкин А.В.и др. Хирургическое лечение больных с неблагоприятными последствиями позвоночно-спинномозговой травмы. Травматология и ортопедия России. 2010. №2 (56). С. 51-54.

48. Млявых С.Г., Морозов И.Н. Дифференцированная тактика хирургического лечения пострадавших с травмой грудного и поясничного отделов позвоночника. Травматология и ортопедия России. 2008. №3. C. $99-100$.

49. Млявых С.Г., Перльмуттер О.А. Дифференцированная хирургическая тактика при нестабильных переломах грудного и поясничного отделов позвоночника. Нижегородский медицинский журнал. 2006. №S. C. 50-53.

50. Мартикян А.Г., Гринь А.А. Диагностика, патогенез и лечение повреждений твердой мозговой оболочки при позвоночноспинномозговой травме. Нейрохирургия. 2018. T.20. №2. C. 74-82.

51. Гринь А.А., Богданова О.Ю., Кайков А.К., Кордонский А.Ю. Хирургическое лечение пациентов с множественной позвоночноспинномозговой травмой на грудном и поясничном уровнях (обзор литературы). Нейрохирургия. 2018. Т.20. №1. С. 64-75.

52. Рузиев Х.Х., Басков А.В., Басков В.А., Древаль О.Н., Дракин И.А. Лечение неосложненных компрессионных переломов позвоночника. Вопросы нейрохирургии им. Н.Н. Бурденко.
2019. T.83. №2. C. 66-70.

53. Якушин О.А., Новокшонов А.В., Федоров М.Ю. Случай двухэтапного хирургического лечения пациентки с осложненным переломом позвоночника поясничного уровня. Сибирское медицинское обозрение. 2018. №6 (114). С. 78-83.

54. Якушин О.А., Пронских А.А., Новокшонов А.В., Федоров М.Ю. Тактика этапного хирургического лечения позвоночноспинномозгой травмы при политравме. Политравма. 2015. №3. С. 16-23.

55. Якушин О.А., Новокшонов А.В., Глебов П.Г., Китиев И.Б.Г. Случай лечения пациента С позвоночно-спинномозговой травмой на уровне грудопоясничного перехода. Политравма. 2013. №1. С. 73-79.

56. Гайдар Б.В., Дулаев А.К., Орлов В.П., Надулич К.А., Теремшонок А.В. Хирургическое лечение пациентов с повреждениями позвоночника грудной и поясничной локализаций. Хирургия позвоночника. 2004. №3. С. 40-45.

57. Федоров М.Ю., Якушин О.А., Ванеев А.В., Крашенинникова Л.П. Случай успешного комплексного лечения пациентки с позвоночно-спинномозговой травмой на грудном уровне при политравме. Политравма. 2017. №3. С. 64-69.

58. Дзукаев Д.Н., Хорева Н.Е. Нестабильные повреждения грудопоясничного отдела позвоночника - возможно ли решение всех проблем одной операцией? Нейрохирургия. 2007. №4. C. 29-35.

59.КрыловВ.В.,ГриньА.А., КайковА.К.,Ощепков С.К., Львов И.С. Современные принципы в хирургии травм и заболеваний позвоночника. Журнал им. Н.В. Склифосовского Неотложная медицинская помощь. 2014. №4. С. 36-41.

60. Гринь А.А., Ощепков С.К., Кайков А.К., Алейникова И.Б. Видеоэндоскопический способ лечения повреждений и заболеваний позвоночника. Нейрохирургия. 2013. №1. С. 53-58.

\section{Статья поступила в редакцию 27.09.2019}

\section{Координаты для связи}

Яриков Антон Викторович, к.М.Н., нейрохирург и травматолог-ортопед ФБУЗ «ПОМЦ» ФМБА, ГБУЗ НО «Городская клиническая больница №39». г. Нижний Новгород. E-mail: antonyarikov@mail.ru

Перльмуттер Ольга Александровна, д.м.н., профессор, заслуженный врач Российской Федерации, нейрохирург ГБУЗ НО «Городская клиническая больница №39». г. Нижний Новгород. 
Фраерман Александр Петрович, д.м.н., профессор, заслуженный деятель науки РФ, нейрохирург ГБУЗ НО «Городская клиническая больница №39» г. Нижний Новгород.

Соснин Андрей Геннадьевич, к.м.н., травматолог-ортопед ФБУЗ «ПОМЦ» ФМБА.

Бояршинов Алексей Андреевич, заочный аспират ФГБОУ ВО «Приволжский исследовательский медицинский университет», нейрохирург ГБУЗ НО «Городская клиническая больница №39».

Гунькин Иван Владимирович, к.м.н., нейрохирург ГБУЗ МО «Мордовская республиканская центральная клиническая больница».

Тихомиров Сергей Евгеньевич, к.м.н., нейрохирург ГБУЗ НО «Городская клиническая больница №39».

Почтовый адрес ГБУЗ НО «Городская клиническая больница №39»: 603028, г.Нижний Новгород, Московское шоссе, 144.

Почтовый адрес ФБУЗ «ПОМЦ» ФМБА:

Нижний Новгород, ул. Ильинская, д. 14.

Почтовый адрес ГБУЗ МО «Мордовская республиканская центральная клиническая больница»: 430001, г. Саранск ул. Победы, д. $14 / 5$

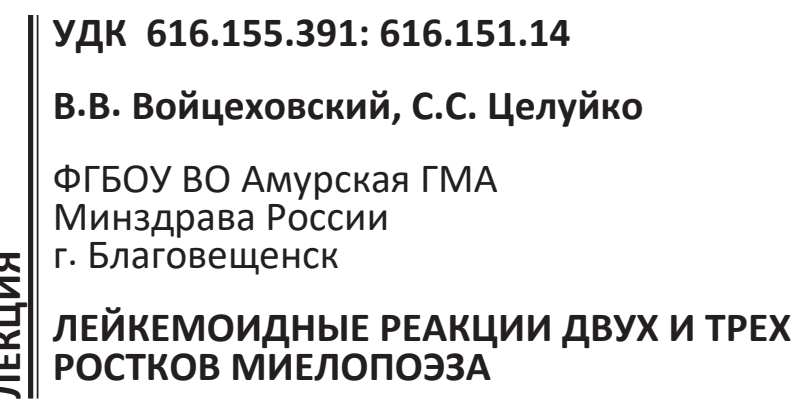

Лейкемоидные реакции представляют собой изменения в составе и структуре клеток крови, напоминающие лейкозы и другие опухоли кроветворной системы, но не трансформирующиеся в ту опухоль, на которую они похожи [1]. В гистопатогенезе лейкемоидных реакций и лейкозов имеются черты сходства, но глубокой этиопатогенетической общности у этих двух процессов нет. Лейкозы - это неоплазия крови; лейкемоидная реакция, это, по словам И.А. Кассирского (1970), «воспаление крови» [8]. Лейкемоидные реакции - это патологическое состояние, при котором, несмотря на повышенное содержание лейкоцитов с возможным сдвигом формулы не наблюдаются явления аплазии, метаплазии и гиперплазии кроветворных органов (недоразвития, измененного и увеличенного образования клеток крови). Лейкемоидные реакции не являются самостоятельным заболеванием в отличие от лейкоза, а носят вторичный симптоматический характер, причем, нередко очевидна причина, индуцировавшая развитие лейкемоидной реакции. Как правило, лейкемоидные реакции возникают вследствие воздействия на организм бактериальных, вирусныхинфекций, чрезвычайных стрессорных раздражителей, а также разнообразных патогенных факторов бактериальной и небактериальной природы, вызывающих сенсибилизацию организма. С устранением действия основного причинного фактора возникает и быстрая нормализация состава периферической крови. Для лейкемоидной реакции не характерны признаки опухолевой прогрессии, свойственные лейкозам, в связи с чем при них не возникают анемии и тромбоцитопении метапластического характера. Являясь гематологическим проявлением многих соматических заболеваний, лейкемоидные реакции встречаются гораздо чаще, чем соответствующие варианты лейкозов. От осведомленности врачей в области реактивных изменений со стороны

Резюме В работе представлены современные данные о лейкемоидной реакции 2 и 3 ростков миелопоэза. Дана характеристика наиболее распространенных заболеваний, протекающих с подобными изменениями в периферической крови.

Ключевые слова: лейкемоидная реакция 2 и 3 ростков миелопоэза. 